\title{
A seroepidemiological study of cytomegalovirus and Epstein-Barr virus in rheumatoid arthritis and sicca syndrome
}

\author{
P J W VENABLES, 1 M G R ROSS, ${ }^{2}$ P J CHARLES, ${ }^{1}$ R D MELSOM, \\ P D GRIFFITHS, ${ }^{2}$ AND R N MAINI
}

From the ' Kennedy Institute of Rheumatology, 6 Bute Gardens, London W6; and the ${ }^{2}$ Department o. Virology, Royal Free Hospital, Pond Street, London NWI

SUMMARY Antibodies to cytomegalovirus (CMV) and Epstein-Barr virus capsid antige $\overrightarrow{\mathbf{T}^{4}}$ (EBVCA) were examined in 41 patients with rheumatoid arthritis (RA), 26 patients with primary sicca syndrome, and 26 healthy subjects of similar age and sex. IgG antibody titres to EBVCA and CMV were similar in all three groups, apart from a trivial increase of antibodies to EBVCA. in RA. False positive IgM anti-CMV antibodies detected in serum from one patient with siccz syndrome and 20 patients with RA were shown to be due to rheumatoid factors. These data diof not support recent suggestions that patients with these diseases showed exaggerated immunolo $\overline{\bar{B}}$ gical responses to either virus and emphasised the need to incorporate adequate laboratory an $\Phi$ disease controls when seroepidemiological studies are performed on sera containing rheumatgid factors and autoantibodies.

The Epstein-Barr virus (EBV) and cytomegalovirus (CMV) are candidate agents for the aetiology of rheumatoid arthritis (RA) and sicca syndrome (SS). Both viruses infect salivary glands and both, once infection has been established, persist for life and could act as triggers for the immunological abnormalities seen in these diseases.

Seroepidemiological evidence for the involvement of EBV in RA has been suggested by the finding of higher antibody titres to Epstein-Barr viral capsid antigen (EBVCA),${ }^{1-3}$ Epstein-Barr nuclear antigen (EBNA), ${ }^{4}$ and early antigen. ${ }^{2}{ }^{3}$ However, in these studies the titre differences were small (usually about one doubling dilution) and there was disagreement about which of the EBV determined antigens represent the targets for this apparently exaggerated response. There has been agreement that antibodies to rheumatoid arthritis nuclear antigen (RANA), initially described as a precipitin reaction characteristic of $\mathrm{RA},{ }^{5}$ are significantly raised, with values ranging from about $6 \times \log _{2}$ in our own studies, ${ }^{6}$ to $16 \times \log _{2}{ }^{3}$ compared with controls. Recent findings that RANA determinants appear to

Accepted for publication 12 April 1985.

Correspondence to Dr P J W Venables, Kennedy Institute of Rheumatology, 6 Bute Gardens, London W6 7DW. reside on the EBNA polypeptide ${ }^{78}$ suggest that the higher levels of anti-RANA in RA sera could represent a relatively specific immune response t $\$$ part of an EBV related polypeptide rather tha reflecting a generalised hyper-responsiveness to EBV. In the present study we examine this possibif ity by comparing titres of antibodies to EBVCA i our patients with titres in normal subjects to see if like anti-RANA, anti-VCA titres are raised in ou patients.

A possible role for $\mathrm{CMV}$ in sicca syndrome was suggested by Shillitoe et al. ${ }^{9}$ who used an enzyme@ linked immunosorbent assay (ELISA) and claime $\bar{\AA}$ that patients with primary sicca syndrome had raise $\$$ levels of both IgG and IgM antibodies to $\mathrm{CMV}_{D}$ indicating active infection. The IgM antibodies were thought not to be false positives due to rheumatois factors, as the reaction persisted after absorbing the sera with protein A Sepharose. They also found thas antibodies to mumps virus were not raised an\& suggested that their findings indicated a specifio hyper-responsiveness to $\mathrm{CMV}$ in SS, though in this study no disease controls were used.

More recent work suggests that a potential roleq for EBV in SS is also worth investigating. Approximately $40 \%$ of patients with SS have antibodies to La (SS-B). ${ }^{10-13}$ This antigen is involved in proces? 
sing both host and viral ribonucleic acids (RNAs) ${ }^{1+}$ ${ }^{16}$ including EBV RNA,${ }^{1+}$ with which it forms stable complexes. It is possible that $\mathrm{La}$, a host protein, may become antigenic when it forms such complexes.

In this study we compare titres of antibodies to EBVCA and CMV in patients with RA, SS, and normal controls. This approach allows each patient group to act as a disease control for the group under examination and CMV to act as a relevant specificity control for EBV and vice versa, as both are herpes viruses. By these means we examined whether there was any seroepidemiological evidence for a role for either virus in SS or RA.

\section{Patients and methods}

\section{PATIENTS AND SERA}

Normal sera were taken from 26 healthy adult volunteers (three male and 23 female) with a mean age of 42.3 years. Twenty-six patients with sicca syndrome comparable for age (mean 45.5 years) and sex (male:female 1:25) and 41 older patients with RA (mean age 60.9 years, male:female 9:38) were coded and assayed for titres of antibodies to CMV and EBV without knowledge of the diagnosis. Three of the RA sera that were examined for anti-CMV were not assayed for anti-EBVCA; otherwise all sera were examined in both assays.

Sicca syndrome was diagnosed only if all three of the following were found: $(a)$ a complaint of dry eyes or mouth, or both; $(b)$ a positive Schirmer's test (less than $10 \mathrm{~mm}$ in both eyes); and (c) rose bengal staining or positive lip biopsy, or both. Patients were excluded if they fulfilled more than three American Rheumatism Association (ARA) criteria for systemic lupus erythematosus. ${ }^{17}$ None of the patients with SS was receiving treatment with steroids or cytotoxic drugs. All the patients with RA fulfilled ARA criteria for classical or definite RA. ${ }^{18}$ Nineteen of the patients were being treated, or had been treated, with gold or penicillamine, eighteen with steroids and/or cytotoxic drugs, and five with nonsteroidal anti-inflammatory agents only.

\section{SEROLOGICAL STUDIES}

Titres of IgG antibodies to EBVCA were measured by indirect immunofluorescence, with doubling dilutions of sera from an initial serum dilution of $1: 8 .^{6}$

Antibodies to CMV were measured by a solid phase radioimmunoassay, and rheumatoid factors were depleted by adsorption with IgG coated latex beads as previously described ${ }^{19-21}$ Antibodies to $\mathrm{La}$ were detected by counterimmunoelectrophoresis with rabbit thymus acetone powder and their identity confirmed with precipitin lines of identity on immunodiffusion. ${ }^{13}$
The Wilcoxon rank sum test and $\chi^{2}$ test were used for the statistical analysis of differences in titres between the different disease groups.

\section{Results}

RHEUMATOID ARTHRITIS

The $\log _{2}$ geometric mean titre (GMT) of antibodies to EBVCA was virtually identical $(7 \cdot 66)$ to SS $(7 \cdot 45)$ and normal controls (7.42) ( $p$ - not significant) (Fig. 1). The titres did not correlate with the presence of extra-articular disease, including Sjögren's syndrome. Patients treated with gold or penicillamine had a higher GMT (8.35) compared with the remainder (7.05) ( $p$ - not significant, not shown). The frequency of IgG anti-CMV antibodies was higher in the RA group $(68 \%)$ compared with the others $(50 \%)$, but the GMT of the positive sera was the same (Fig. 2). Twenty sera were positive in the assay for IgM antibodies to CMV. Of these, 16 were abolished and four reduced by adsorption with latex $\mathrm{IgG}$. Three of the four still positive after latex IgG

RECIPROCAL TITRES OF ANTI-EBVCA

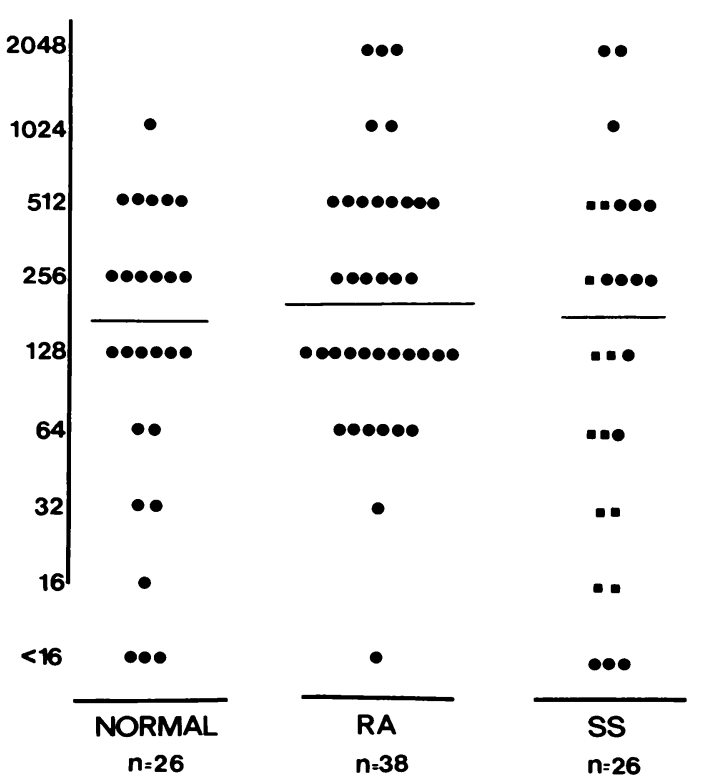

Fig. 1 Reciprocal titres of $\operatorname{Ig} G$ antibodies to Epstein-Barr virus capsid antigen ( $E B V C A$ ) in sera from patients with rheumatoid arthritis, sicca syndrome, and normal controls. The geometric mean titres of the antibody positive sera are shown as the horizontal lines. Sera from SS patients containing anti-La are shown as $\mathbf{\square}$. 


\section{ANTIBODIES TO CMV}

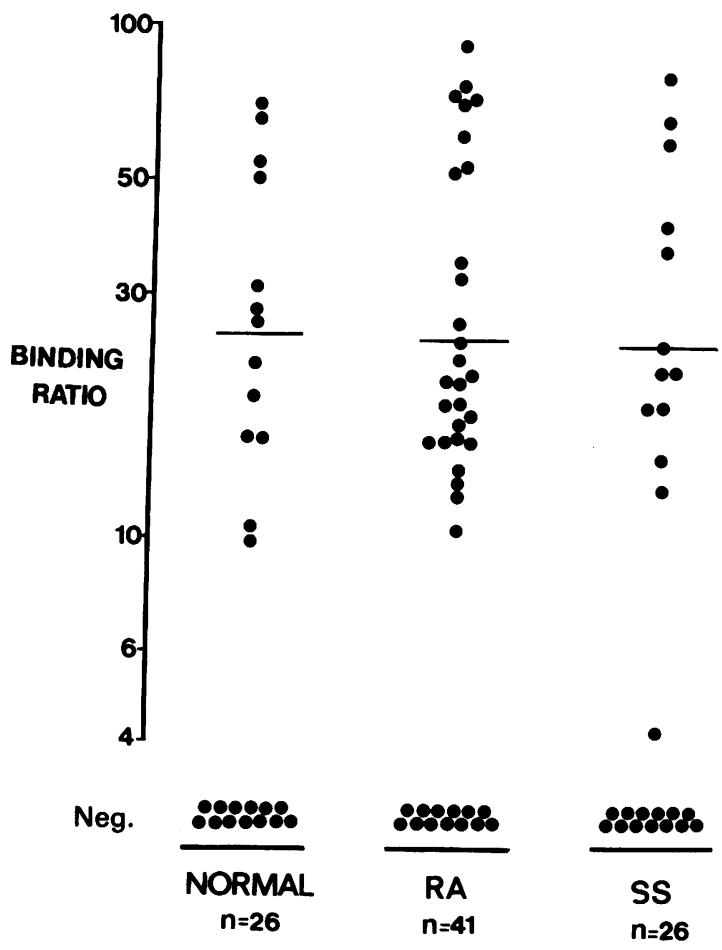

Fig. 2 IgG antibodies to CMV expressed as a test/control binding ratio in sera from patients with rheumatoid arthritis, sicca syndrome, and normal controls.

treatment were abolished with subsequent adsorptions.

\section{SICCA SYNDROME}

The frequency $(50 \%)$ and GMT of IgG anti-CMV were identical in SS to those of a normal control group of similar age and sex distribution (Fig. 2), and there was no difference in titre in the sera containing anti-La (not shown). False positive IgM anti-CMV antibodies that disappeared after adsorption with latex IgG were detected in one serum. The prevalence and mean titres of antiEBVCA were similar to those of the controls (Fig. 1). All of the sera containing anti-La contained IgG antibodies to EBVCA, though the mean $\log _{2}$ GMT tended to be lower, 6.36 (p - not significant).

\section{Discussion}

In this report the titre of antibodies to EBVCA was higher in the sera from patients with RA, though it was marginal $\left(0.25 \log _{2}\right)$ and in our study could be related to treatment with gold and penicillaminew Much larger numbers would be needed in our work and previous studies to confirm this and to ascertaif whether the effect was directly due to the treatmen or to the possibility that the gold or penicillamine treated group represented a different population of patients.

The difference in anti-EBVCA titres between R and normal sera was trivial compared with the $6 \log -$ differences in anti-RANA titres which we have previously described. ${ }^{6} \mathrm{~A}$ similar dissociation be $\vec{\omega}$ tween anti-EBVCA and anti-RANA titres was reported in a previous study ${ }^{3}$ where a $1 \log _{2}$, i.e., on doubling dilution, difference in anti-VCA titres was observed compared with an approximately 16-fold difference in anti-RANA titres. This supports the hypothesis that the increased anti-RANA titres if $\mathrm{RA}$ are not due to a generalised hyper $\mathrm{r}_{0}$ responsiveness to $\mathrm{EBV}$, particularly as patients with Burkitt's lymphoma, in whom active EBV infection is marked by very high titres of anti-EBVCA an $\Phi$ anti-EBNA, were reported as negative for anti RANA antibodies. ${ }^{22}$ The recent finding that deter minants for RANA can be detected on the EBNA polypeptide by immunoblotting ${ }^{78}$ suggests anothero apparent discrepancy, as anti-EBNA titres in KA are usually found to be normal or only margin raised, ${ }^{1}{ }^{3} 4$ and we have reported RA sera negative for anti-EBNA antibodies in which anti-RANA was detected both by immunodiffusion and immunoblotting. ${ }^{6} 7$ These findings can be explaineक्ष by the possibility that anti-RANA antibodies reace with determinants on the polypeptide that are different from those detected by anti-EBNA. Alter natively, as we have previously suggested ${ }^{7}$ sera fron patients with RA may contain antinuclear anti bodies that cross react with the EBNA polypeptide The second mechanism is supported by the recent description $^{23}$ of a 62000 host protein that shares. antigenic components with EBNA, which maj reflect similarities between part of the EBV genome and host DNA. ${ }^{24}$ We suggest that the RANA-antio RANA reaction may be more complex than pre viously thought, and the higher anti-RANA titres in RA may not be due to a generalised hyper responsiveness to EBV.

The prevalence and titre of anti-CMV in SS were the same as in the normal controls. IgM antibodies which were mainly detected in the RA group, were false positives due to rheumatoid factors. We are unable to reconcile our results with those of Shillitoe et al. ${ }^{9}$ who found that two thirds of their patients? with SS had IgM antibodies to CMV and that the mean titre of IgG antibodies was significantly higher than for normal controls. The reason for the 
differences in our results is unclear and must be due to either differences in the assays or to differences in the patient population.

Unlike the ELISA reported by Shillitoe et al. ${ }^{9}$ the radioimmunoassay described in this report has been extensively examined in seroepidemiological studies. ${ }^{19-21}$ Since both EBV and CMV are herpesviruses associated with long term chronic infection, leading to a persistent antibody response, we suggest that an important criterion for a valid assay is that it should be able to show a distinction between individuals infected with the virus and those who are not. Such a distinction is clearly presented here, though it was not apparent in the data shown in the ELISA assay, ${ }^{9}$ where both control and SS sera showed a continuous range of values from zero to strongly positive. This suggests that serum factors other than anti-CMV may have contributed to the findings of Shillitoe et al.

Although only one patient with SS in our study had false positive IgM anti-CMV antibodies, the high frequency in RA suggested that it was due to rheumatoid factors acting as a bridge between IgG antibodies and the conjugate. This was confirmed by disappearance of the IgM reaction after adsorption with latex IgG. Approximately two thirds of patients with SS have rheumatoid factors, and the majority have raised serum levels of $\mathrm{IgG}$. It is possible that the procedure used by Shillitoe et al. (absorption of $\mathrm{IgG}$ by protein $\mathrm{A}$, which was apparently adequate for normal sera) ${ }^{9}$ might not have excluded interfering rheumatoid factors or removed high levels of IgG from these pathological sera. An additional factor, which makes interpretation of their data difficult, is that the sensitivity and specificity of their assay were not validated with $\mathrm{IgM}$ positive control sera from patients known to have active CMV infection.

An alternative explanation for our failure to confirm evidence of active CMV infection in SS is that the sera used in our study came from a different population of patients, an issue which would have been resolved by an exchange of sera with the group in the original report, ${ }^{9}$ though these are apparently not available for further study.

The geometric mean titre of anti-EBVCA in SS was also identical to the controls, though those sera that also contained anti-La (SS-B) tended to be lower. One reason for this low titre may be the strong background cytoplasmic immunofluorescence produced by anti-La itself, demonstrable with monoclonal antibodies tested on lymphoblastoid cell lines, ${ }^{25}$ which may have masked specific VCA staining. Although this does not provide evidence against EBV as a possible aetiological agent in SS, it indicates the limitations of seroepi- demiological techniques for investigating a viral aetiology for connective tissue diseases. These findings, together with our negative data for CMV, highlight the importance of incorporating adequate laboratory and disease controls when titres of antibodies to viruses are measured in sera containing autoantibodies and rheumatoid factors.

Part of this work was supported by the Arthritis and Rheumatism Council of Great Britain. We gratefully acknowledge the donation of sera from eight patients with primary sicca syndrome by $\mathrm{Dr}$ David Isenberg, University College Hospital, London.

\section{References}

1 Alspaugh M A, Henle W. Significance of elevated Epstein-Barr virus antibodies in serum or synovial fluids from rheumatoid arthritis patients [Abstract]. Arthritis Rheum 1980; 22: 587.

2 Alspaugh M A, Henle G, Lennette E T, Henle W. Elevated levels of antibodies to Epstein-Barr virus antigens in patients with rheumatoid arthritis. $J$ Clin Invest 1981; 67: 1134-40.

3 Ferrel F B, Aitcheson C T, Pearson G R, Tan E M. Seroepidemiological study of relationships between Epstein-Barr virus and rheumatoid arthritis. J Clin Invest 1981; 67: 681-7.

4 Catalano M A, Carson D A. Slovin S F, Richaman D D, Vaughan J H. Antibodies to Epstein-Barr virus determined antigens in normal subjects and patients with seropositive rheumatoid arthritis. Proc Natl Acad Sci USA 1979; 76: 681-7.

5 Alspaugh M A. Tan E M. Serum antibody in rheumatoid arthritis reactive with a cell associated antigen. Arthritis Rheum 1976; 19: 711-9.

6 Venables P J W, Roffe L M, Erhardt C C, Maini R N, Edwards J M B. Porter A D. Titres of antibodies to RANA in rheumatoid arthritis and normal sera: relationship to EpsteinBarr virus infection. Arthritis Rheum 1982; 24: 1459-64.

7 Venables P J W. Smith P R. Maini R N. Rheumatoid arthritis nuclear antigen and Epstein-Barr virus. Arthritis Rheum 1984; 27: 476-7.

8 Billings P B, Hoch S O, White P J, Carson D A, Vaughan J H. Antibodies to Epstein-Barr nuclear antigen and to the rheumatoid arthritis nuclear antigen identify the same polypeptide. Proc Natl Acad Sci USA 1983; 80: 7104-8.

9 Shillitoe E J, Daniels T E. Whitcher J P. Strand C V. Talal N, Greenspan J S. Antibody to cytomegalovirus in patients with Sjögren's syndrome: as detected by enzyme linked immunosorbent assay. Arthritis Rheum 1982; 25: 260-5.

10 Mattioli M, Reichlin M. Heterogeneity of RNA protein antigens reactive with sera of patients with systemic lupus erythematosus. Arthritis Rheum 1984; 17: 421-9.

11 Alspaugh M A, Talal N, Tan E M. Differentiation and characterisation of autoantibodies and their antigens in Sjögren's syndrome. Arthritis Rheum 1976; 19: 216-22.

12 Akisuki M, Powers R, Holman H R. A soluble acidic protein of the cell nucleus which reacts with serum from patients with systemic lupus erythematosus and Sjögren's syndrome. J Clin Invest 1977; 59: 264-72.

13 Venables P J W, Charles P J, Buchanan R R C, et al. Quantitation and detection of isotypes of anti-SS-B antibodies by ELISA and Farr assays using affinity purified antigens. Arthritis Rheum 1983; 26: 146-55.

14 Lerner M R. Andrews N C, Miller G. Steitz J A. Two small RNAs encoded by Epstein-Barr virus and complexed with protein are precipitated by antibodies from patients with systemic lupus erythematosus. Proc Natl Acad Sci USA 1981; 78: 805-9.

15 Kurilla M G, Keene J D. The leader RNA of vesicular stomatitis virus is bound by a cellular protein reactive with antiLa lupus antibodies. Cell 1983; 34: 837-45. 
16 Francoeur A M, Mathews M B. The interaction between VA RNA and the lupus antigen La: formation of a ribonucleoprotein particle in vitro. Proc NatI Acad Sci USA 1982; 79: 6772-6.

17 Tan E M, Cohen A S, Fries J F, et al. The 1982 revised criteria for the classification of systemic lupus erythematosus. Arthritis Rheum 1982; 25: 1271-7.

18 Ropes M W, Bennet G A, Cobb S, Jacox R, Jessar R A. Revision of diagnostic criteria for rheumatoid arthritis. Bull Rheum Dis 1959; 9: 175-6.

19 Booth J C, Hannington G, Bakir T M F, et al. Comparison of enzyme-linked immunosorbent assay, radioimmunoassay, complement fixation, anticomplement immunofluorescence and passive haemagglutination techniques for detecting cytomegalovirus IgG antibody. J Clin Pathol 1982; 35: 1345-8.

20 Griffiths P D, Kangro H O. A users guide to the indirect solidphase radioimmunoassay for the detection of cytomegalovirusspecific IgM antibodies. J Virol Methods 1984; 8: 271-82.
21 Griffiths P D, Stagno S, Pass R F, Smith R J, Alford C A Congentital cytomegalovirus infection: diagnostic and prog nostic significance of the detection of specific immunoglobulin M antibodies in cord serum. Pediatrics 1982; 69: 544-9.

22 Alspaugh M A, Jensen F C, Rabin H, Tan E M. Lymphocytes transformed by Epstein-Barr virus: induction of nuclear antige reactive with antibody in rheumatoid arthritis. $J$ Exp Med 1978 음 147: 1018-26.

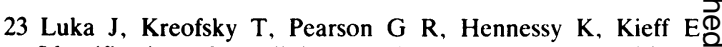
Identification of a cellular protein that cross-reacts with the Epstein-Barr virus nuclear antigen. $J$ Virol 1984; 52: 833-8

24 Hennessy K, Heller M, van Santen V, Kieff E. Simple repea $\vec{b}$ array in Epstein-Barr virus DNA encodes part of the Epstein Barr nuclear antigen. Science 1983; 220: 1396-8.

25 Smith P R, Williams D W, Venables P J W, Maini R N Monoclonal antibodies to SS-B (La) antigen. J Immuno Methods 1985; 77: 63-76.

\section{Book review}

Perspectives in Rheumatology 1984. Eds. John Decker and Tom Scott. Pp. 266. £30.00. Current Medical Literature: London. 1984.

This is a beautifully produced book; well bound, good quality paper, pleasing typeface, and excellent layout. It differs from other review volumes-in addition to 'standard' commissioned review articles a large selection of references from many journals has been grouped into topics and a short resumé of each set of papers has been provided by one of the associate editors. One might expect such a wide coverage to be sketchy, but the whole volume is large enough to be very comprehensive.

However, although the Preface suggests that this might be the first of a biennial venture and claims that the literature review covers the last two years, this is sadly not true. By the time the book has hit the shops-1985-no reference is later than 1983 and many date back five years or more. Though this allows a broad perspective, to be always two years behind is a fairly serious problem for a supposedly current review.

Nonetheless I enjoyed two articles; John Decker's own, very readable one on treatment in rheumatoid arthritis and Hunder and Hall's article on disease classification, referring among others to three papers on juvenile arthritis which I had missed and will be getting my librarian to cosy $\overrightarrow{ }$ Several other references in various topic groups had passed me by. I admit to skimming the long systemic luĝts erythematosus section, partly because it was so awf boring and partly because having only seen one patiens with the disease last year I couldn't really get up an feeling of need.

Now rheumatologists world wide receive a bimonthl digest from CML, circulated under sponsorship, identicaf in concept to this compendium, and with the same team o⿸\zh14 associate editors. Do we need the compendium as well $\bar{P}$ Frankly I don't think the format works in the large book. I is too dated and too indigestible. Whereas the bimonthle version can be quickly enjoyed, the book demands की certain dedication, like homework. I am told that it mañ also be distributed free, courtesy of the pharmaceuticat industry and would be an elegant addition to a unit library? but I doubt if it would be opened very often. It is tod specialised for most postgraduate centre libraries and in these straightened times I can think of better buys.

Consultant Rheumatologist,

ANDREW BAMII.

Brook General Hospital,

London SE18. 